\title{
Azithromycin for COVID-19: More Than Just an Antimicrobial?
}

\author{
Nathalie Bleyzac ${ }^{1} \cdot$ Sylvain Goutelle $\mathrm{e}^{1,2}\left(\mathbb{0} \cdot\right.$ Laurent Bourguignon $^{1,2} \cdot$ Michel Tod $^{1,2}$
}

Published online: 12 June 2020

(c) Springer Nature Switzerland AG 2020

The COVID-19 infection due to severe acute respiratory syndrome coronavirus 2 (SARS-CoV-2) is a major public health issue worldwide, as no vaccines or drugs for prevention and treatment have been approved so far, except remdesivir that has been recently authorized for use in the USA and Japan [1]. Many clinical studies are ongoing. Most of them evaluate established antiviral drugs such as lopinavir/ritonavir, and chloroquine (CQ) or its derivative hydroxychloroquine (HCQ), which have shown in vitro antiviral activity against SARS-CoV-2 [2]. Because SARS coronavirus infections are known to induce inflammation and subsequent tissue damage in the lungs in moderate-to-severe cases [3], using immunomodulating drugs could provide a benefit in the treatment of COVID-19. Drugs with the most relevant immunomodulatory profile remain to be found. We believe the antibacterial macrolide azithromycin (AZM) has a special and interesting profile in this search for drug therapy for COVID-19. We discuss below the arguments for this claim.

It has been shown that AZM has significant antiviral properties. In contrast with CQ or HCQ, its antiviral activity has been shown in vitro and/or in vivo on a large panel of viruses: Ebola, Zika, respiratory syncytial virus, influenzae H1N1 virus, enterovirus, and rhinovirus [4-13]. Its activity against respiratory syncytial virus has been demonstrated in a randomized study in infants [10]. Azithromycin exhibited a synergistic antiviral effect against SARS-CoV-2 when combined with HCQ both in vitro [11] and in a clinical setting [13]. Of note, the pre-print version of the article from Andreani et al. [14] also reported a significant antiviral effect of AZM alone on SARS-CoV-2. The mechanisms of the antiviral effect of AZM support a large-spectrum antiviral

Sylvain Goutelle

sylvain.goutelle@chu-lyon.fr

1 Service de Pharmacie, Hospices Civils de Lyon, Groupement Hospitalier Nord, Hôpital Pierre Garraud, 136 rue du Commandant Charcot, 69005 Lyon, France

2 Univ Lyon, Université Lyon 1, ISPB, Faculté de Pharmacie de Lyon \& UMR CNRS 5558, Laboratoire de Biométrie et Biologie Evolutive, Lyon, France activity. Azithromycin appears to decrease the virus entry into cells $[2,8]$. In addition, it can enhance the immune response against viruses by several actions. Azithromycin up-regulates the production of type I and III interferons (especially interferon- $\beta$ and interferon- $\lambda$ ), and genes involved in virus recognition such as MDA5 and RIG-I [7, $12,13,15,16]$. These mechanisms are universally involved in the innate response against infectious agents, and potentially against SARS-CoV-2.

The immunomodulation properties of AZM are the rationale of its use against inflammatory manifestations leading to interstitial lung disease [17, 18]. SARS-CoV-2 has been shown to exacerbate the inflammatory response of its host, leading to serious damage of lung interstitial tissue [19]. Patients with severe COVID-19-associated pneumonia may exhibit a syndrome of systemic hyper-inflammation designated as a cytokine storm [20]. Cytokine profiles of patients with severe COVID-19 have been compared to those of patients with moderate forms and have shown a notable increase in some pro-inflammatory cytokines such as interleukin (IL)-1 $\beta$, IL-2, IL-6, IL-8, IL-10, IL-17, and tumor necrosis factor- $\alpha$ [19-21]. Therapeutic approaches targeting only IL- 6 have been proposed but may be double-edged because the timing of its administration might adversely affect viral clearance [21]. By contrast, AZM shows an interesting immunomodulatory profile by inhibiting several cytokines involved in COVID-19 severe respiratory syndrome. Indeed, AZM regulates and/or decreases the production of IL-1 $\beta$, IL-6, IL-8, IL-10, IL-12, and IFN- $\alpha$ $[10,22,23]$. Hydroxychloroquine also has immunomodulatory effects, and has been reported to decrease IL-1, IL-2, IL-6, IL-17, IL-22, IFN- $\alpha$, and tumor necrosis factor [24, 25]. Azithromycin and HCQ both decrease the production of major inflammatory cytokines such as IL-1 and IL-6. However, the different profiles of immunomodulation between the two drugs may be crucial for selecting one of them for the treatment of COVID-19, in relation to the pathogenicity of the virus. Indeed, HCQ may decrease IL-2 levels but not AZM, while AZM may decrease IL-8 levels but not HCQ. 
Interleukin-2 is a key cytokine involved in the host innate immune response to bacterial or viral pathogens by inducing T-lymphocyte proliferation and differentiation [26]. Despite elevated IL-2 soluble receptor levels reported by Huang et al. in patients with COVID-19 [19], lymphocyte counts were at the lower limit and subsets were deeply modified [27]. Qin et al. showed that B cells, T-helper cells, T-regulatory cells, and natural killer counts were significantly decreased in patients with COVID-19, with a more pronounced decline in the severe cases [27]. A lower count of memory T cells was also observed in patients with COVID-19, which raises concerns about limited immunization against the virus [27]. Interleukin-2 production, enhanced by a native immune response in patients with COVID-19, should be maintained to favor an adaptive antiviral immune response and allow a sufficient production of adequate memory $\mathrm{T}$ and natural killer cells, but also induce T-regulatory cells to control inflammation. Chloroquine (and possibly HCQ) has been shown to inhibit IL-2 production [27, 28], while AZM showed an opposite action [29]. Hence, AZM could allow a sufficient memory T-cell count to be maintained and a better immunization. Otherwise, IL-8 is involved in neutrophil chemotaxis facilitating the lung infiltration and macrophage activation-like syndrome observed in patients with severe disease $[20,30]$. Therefore, the inhibitory effect of AZM on IL-8 may also be of interest for COVID-19 therapy.

Another property of AZM is its antibacterial effect, which may be most interesting to prevent or treat co-infection by bacteria and SARS-CoV-2. Recent data suggested that anaerobic bacteria of lung microbiota may be involved in the SARS-CoV-2 pathogenesis. Prevotella cells, which have been found in abnormal quantities in patients with severe disease, could internalize SARS-Cov2 and enhance its pathogenicity [31-33]. Prevotella spp. are commensal anaerobic bacteria in the lungs [33]. They are involved in idiopathic inflammatory lung diseases, notably by facilitating IL-6 and IL-8 production [34-36]. Azithromycin is a possible treatment for Prevotella infections and decreases Prevotella-induced inflammation [37, 38].

Azithromycin has other attractive pharmacological and therapeutic properties in the search for COVID-19 drug therapy. It is extensively distributed into tissue, especially in lungs where average concentrations in both extracellular fluids and within cells are much higher than in plasma [39].

Azithromycin is approved in both adults and children aged $\geq 6$ months. First approved in the USA in 1991, it has been administered to numerous patients and its tolerance is well known. The most frequent adverse drug reactions are related to the gastrointestinal tract (e.g., nausea, vomiting, diarrhea, or abdominal pain). Those are mild to moderate in severity and reversible. Like CQ and HCQ, AZM may prolong the QT interval but clinical consequences such as arrhythmias are rare. The arrhythmogenic potential of AZM appears to be lower than that of other macrolides [40]. Therefore, the risk of interactions with other drugs that prolong the QT interval is arguably lower as well.

Unlike other macrolide antibiotics such as erythromycin and clarithromycin, AZM is only a weak cytochrome P450 inhibitor [41]. Clinically relevant drug-drug interactions with AZM as the perpetrator drug appear to be rare. Interestingly, a study investigated the effect of AZM on CQ pharmacokinetics and reported no significant drug interaction [42].

A retrospective study has evaluated the effect of various macrolides including AZM in critically ill patients with MESR-CoV and reported no significant benefits [43]. However, AZM alone was used in a limited number of patients in this study, and late in the course of MERS-CoV infection. This uncontrolled study has many confounders, including co-treatment and is of low evidence. The optimal time for the introduction of drug therapy in COVID-19 including AZM is uncertain and needs to be investigated as well. A recent observational study reported data on AZM used alone in patients with COVID-19 [44]. Patients were treated immediately after diagnosis and received HCQ plus AZM or HCQ alone, or AZM alone. The mortality rates adjusted for comorbidities and demographics at 21 days were $22.5 \%$ (95\% confidence interval 19.7-25.1) in patients with HCQ plus AZM, 18.9\% (95\% confidence interval 14.3-23.2) in patients with HCQ alone, and 10.9\% (95\% confidence interval 5.8-15.6) in patients with AZM alone [43]. These encouraging results need to be confirmed by further randomized studies. Considering the uncertain efficacy of most agents currently in use in patients with COVID-19 and the greater risk of adverse drug reactions associated with drug combinations [45], we believe that each drug candidate for treating COVID-19 should be first evaluated alone in randomized controlled trials.

To conclude, there are several arguments supporting a potential effectiveness of AZM in SARS-CoV-2 infection, including its antiviral activity and immunomodulatory effects. We believe AZM should be clinically investigated as a monotherapy in patients with SARS-CoV-2 infection.

Author Contributions NB performed the literature search, wrote the draft manuscript, and approved the final version. SG, LB, and MT critically examined the published data, edited the draft manuscript, and approved the final version.

\section{Compliance with Ethical Standards}

Funding This work was not supported by specific funds. It was conducted as part of our routine activity that is funded by Hospices Civils de Lyon and the University of Lyon. 
Conflict of interest Nathalie Bleyzac, Sylvain Goutelle, Laurent Bourguignon, and Michel Tod have no conflicts of interest that are directly relevant to the content of this article.

\section{References}

1. Beigel JH, Tomashek KM, Dodd LE, Mehta AK, Zingman BS, Kali AC, for the ACTT-1 Study Group Members, et al. Remdesivir for the treatment of Covid-19: preliminary report. N Engl J Med. 2020. https://doi.org/10.1056/nejmoa2007764.

2. Yao X, Ye F, Zhang M, Cui C, Huang B, Niu P, et al. In vitro antiviral activity and projection of optimized dosing design of hydroxychloroquine for the treatment of Severe Acute Respiratory Syndrome Coronavirus 2 (SARS-CoV-2). Clin Infect Dis. 2020. https://doi.org/10.1093/cid/ciaa237.

3. Ye Q, Wang B, Mao J. The pathogenesis and treatment of the 'cytokine storm' in COVID-19. J Infect. 2020;80:607-13.

4. Du X, Zuo X, Meng F, Wu F, Zhao X, Li C, et al. Combinatorial screening of a panel of FDA-approved drugs identifies several candidates with anti-Ebola activities. Biochem Biophys Res Commun. 2020;522:862-8.

5. Retallack H, Di Lullo E, Arias C, Knopp KA, Laurie MT, Sandoval-Espinosa $\mathrm{C}$, et al. Zika virus cell tropism in the developing human brain and inhibition by azithromycin. Proc Natl Acad Sci USA. 2016;113:14408-13.

6. Wu YH, Tseng CK, Lin CK, Wei CK, Lee JC, Young KC. ICR suckling mouse model of Zika virus infection for disease modeling and drug validation. PLoS Negl Trop Dis. 2018;12:e0006848.

7. Li C, Zu S, Deng YQ, Li D, Parvatiyar K, Quanquin N, et al. Azithromycin protects against Zika virus infection by upregulating virus-induced type I and III interferon responses. Antimicrob Agents Chemother. 2019. https://doi.org/10.1128/aac.00394-19.

8. Tran DH, Sugamata R, Hirose T, Suzuki S, Noguchi Y, Sugawara A, et al. Azithromycin, a 15-membered macrolide antibiotic, inhibits influenza (H1N1)pdm09 virus infection by interfering with virus internalization process. J Antibiot (Tokyo). 2019;72:759-68.

9. Mosquera RA, De Jesus-Rojas W, Stark JM, Yadav A, Jon CK, Atkins CL, et al. Role of prophylactic azithromycin to reduce airway inflammation and mortality in a RSV mouse infection model. Pediatr Pulmonol. 2018;53:567-74.

10. Beigelman A, Isaacson-Schmid M, Sajol G, Baty J, Rodriguez $\mathrm{OM}$, Leege E, et al. Randomized trial to evaluate azithromycin's effects on serum and upper airway IL-8 levels and recurrent wheezing in infants with respiratory syncytial virus bronchiolitis. J Allergy Clin Immunol. 2015;135:1171-8.

11. Andreani J, Le Bideau M, Duflot I, Jardot P, Rolland C, Boxberger $\mathrm{M}$, et al. In vitro testing of hydroxychloroquine and azithromycin on SARS-CoV-2 shows synergistic effect. Microb Pathog. 2020;25(145):104228.

12. Zeng S, Meng X, Huang Q, Lei N, Zeng L, Jiang X, et al. Spiramycin and azithromycin, safe for administration to children, exert antiviral activity against enterovirus A71 in vitro and in vivo. Int J Antimicrob Agents. 2019;53:362-9.

13. Gautret P, Lagier JC, Parola P, Hoang VT, Meddeb L, Mailhe $\mathrm{M}$, et al. Hydroxychloroquine and azithromycin as a treatment of COVID-19: results of an open-label non-randomized clinical trial. Int J Antimicrob Agents. 2020. https://doi.org/10.1016/j.ijantimica g.2020.105949.

14. Andreani J, Le Bideau M, Duflot I, Jardot P, Rollanda C, Boxberger M, Bou Khalil JY, Baudouin JP, Wurtz N, Rolain JM, Colson P, La Scola B, Raoult D. In vitro testing of hydroxychloroquine and azithromycin on SARS-CoV-2 shows synergistic effect. 2020. https://www.mediterranee-infection.com/wp-content/uploa
ds/2020/03/Andreani-et-al.-Pre-print-V2.pdf. Accessed 27 May 2020.

15. Schögler A, Kopf BS, Edwards MR, Johnston SL, Casaulta C, Kieninger E, et al. Novel antiviral properties of azithromycin in cystic fibrosis airway epithelial cells. Eur Respir J. 2015;45:428-39.

16. Menzel M, Akbarshahi H, Bjermer L, Uller L. Azithromycin induces anti-viral effects in cultured bronchial epithelial cells from COPD patients. Sci Rep. 2016;6:28698.

17. Kawamura K, Ichikado K, Suga M, Yoshioka M. Efficacy of azithromycin for treatment of acute exacerbation of chronic fibrosing interstitial pneumonia: a prospective, open-label study with historical controls. Respiration. 2014;87:478-84.

18. Bush A, Cunningham S, de Blic J, Barbato A, Clement A, Epaud $\mathrm{R}$, on behalf of the chILD-EU Collaboration, et al. European protocols for the diagnosis and initial treatment of interstitial lung disease in children. Thorax. 2015;70:1078-84.

19. Huang C, Wang Y, Li X, Ren L, Zhao J, Hu Y, et al. Clinical features of patients infected with 2019 novel coronavirus in Wuhan, China. Lancet. 2020;395:497-506.

20. Chen G, Wu D, Guo W, Cao Y, Huang D, Wang H, et al. Clinical and immunological features of severe and moderate coronavirus disease 2019. J Clin Investig. 2020;130:2620-9.

21. McGonaglea D, Sharifa K, O'Regand A, Bridgewooda C. The role of cytokines including interleukin-6 in COVID-19 induced pneumonia and macrophage activation syndrome-like disease. Autoimmune Rev. 2020. https://doi.org/10.1016/j.autrev.2020.102537.

22. Cai M, Bonella F, Dai H, Sarria R, Guzman J, Costabel U. Macrolides inhibit cytokine production by alveolar macrophages in bronchiolitis obliterans organizing pneumonia. Immunobiology. 2013;218:930-7.

23. Zarogoulidis P, Papanas N, Kioumis I, Chatzaki E, Maltezos E, Zarogoulidis K. Macrolides: from in vitro anti-inflammatory and immunomodulatory properties to clinical practice in respiratory diseases. Eur J Clin Pharmacol. 2012;68:479-503.

24. Silva JC, Mariz HA, Rocha LF Jr, Oliveira PS, Dantas AT, Duarte $\mathrm{AL}$, et al. Hydroxychloroquine decreases Th17-related cytokines in systemic lupus erythematosus and rheumatoid arthritis patients. Clinics (Sao Paulo). 2013;68:766-71.

25. Durcan L, Petri M. Immunomodulators in SLE: clinical evidence and immunologic actions. J Autoimmun. 2016;74:73-84.

26. Shaw AC, Goldstein DR, Montgomery RR. Age-dependent dysregulation of innate immunity. Nat Rev Immunol. 2013;13:875-87.

27. Qin C, Zhou L, Hu Z, Zhang S, Yang S, Tao Y, et al. Dysregulation of immune response in patients with COVID-19 in Wuhan, China. Clin Infect Dis. 2020. https://doi.org/10.1093/cid/ciaa248.

28. Landewe RB, Miltenburg AM, Verdonk MJ, Verweij CL, Breedveld FC, Daha MR, et al. Chloroquine inhibits T cell proliferation by interfering with IL-2 production and responsiveness. Clin Exp Immunol. 1995;102:144-51.

29. Tomazic J, Kotnik V, Wabers B. In vivo administration of azithromycin affects lymphocyte activity in vitro. Antimicrob Agents Chemother. 1993;37:1786-9.

30. Li CK, Wu H, Yan H, Ma S, Wang L, Zhang M, et al. T cell responses to whole SARS coronavirus in humans. J Immunol. 2008;181:5490-500.

31. Chakrabort YS. Sequencing data $(N=3)$ shows Wuhan coronavirus integration in bacteria (Prevotella mostly). Sequencing artifact - or is the virus infecting both bacterial and human cells? 2020. https://doi.org/10.31219/osf.io/ktngw. Accessed $20 \mathrm{Apr}$ 2020.

32. Chakraborty S. The Wuhan coronavirus has integrated in Prevotella, which possibly causes the observed extreme virulence-as sequencing data from 2 different studies in China and Hong-Kong shows unequivocally. 2020. https://doi.org/10.31219/osf.io/ktngw. Accessed 20 Apr 2020. 
33. Chakraborty S. The 2019 Wuhan outbreak could be caused by the bacteria Prevotella, which is aided by the coronavirus-Prevotella is present (sometimes in huge amounts) in patients from two studies in China and one in Hong Kong. 2020. https://doi. org/10.31219/osf.io/usztn. Accessed 20 Apr 2020.

34. Marsland BJ, Gollwitzer ES. Host-microorganism interactions in lung diseases. Nat Rev Immunol. 2014;14:827-35.

35. Mirković B, Murray MA, Lavelle GM, Molloy K, Azim AA, Gunaratnam C, et al. The role of short-chain fatty acids, produced by anaerobic bacteria, in the cystic fibrosis airway. Am J Respir Crit Care Med. 2015;192:1314-24.

36. Molyneaux PL, Cox MJ, Willis-Owen SAG, et al. The role of bacteria in the pathogenesis and progression of idiopathic pulmonary fibrosis. Am J Respir Crit Care Med. 2014;190:906-13.

37. Mättö J, Asikainen S, Väisänen ML, Von Troil-Lindén B, Könönen E, Saarela M, et al. Beta-lactamase production in Prevotella intermedia, Prevotella nigrescens, and Prevotella pallens genotypes and in vitro susceptibilities to selected antimicrobial agents. Antimicrob Agents Chemother. 1999;43:2383-8.

38. Choi EY, Jin JY, Choi JI, Choi IS, Kim SJ. Effect of azithromycin on Prevotella intermedia lipopolysaccharide-induced production of interleukin-6 in murine macrophages. Eur J Pharmacol. 2014;729:10-6.

39. Rodvold KA, Gotfried MH, Danziger LH, Servi RJ. Intrapulmonary steady-state concentrations of clarithromycin and azithromycin in healthy adult volunteers. Antimicrob Agents Chemother. 1997;41:1399-402.

40. Guo D, Cai Y, Chai D, Liang B, Bai N, Wang R. The cardiotoxicity of macrolides: a systematic review. Pharmazie. 2010;65:631-40.

41. Polasek TM, Miners JO. Quantitative prediction of macrolide drug-drug interaction potential from in vitro studies using testosterone as the human cytochrome P4503A substrate. Eur J Clin Pharmacol. 2006;62:203-8.

42. Cook JA, Randinitis EJ, Bramson CR, Wesche DL. Lack of a pharmacokinetic interaction between azithromycin and chloroquine. Am J Trop Med Hyg. 2006;74:407-12.

43. Arabi YM, Deeb AM, Al-Hameed F, Mandourah Y, Almekhlafi GA, Sindi AA, et al. Macrolides in critically ill patients with Middle East Respiratory Syndrome. Int J Infect Dis. 2019;81:184-90.

44. Rosenberg ES, Dufort EM, Udo T, Wilberschied LA, Kumar J, Tesoriero J, et al. Association of treatment with hydroxychloroquine or azithromycin with in-hospital mortality in patients with COVID-19 in New York State. JAMA. 2020. https://doi. org/10.1001/jama.2020.8630.

45. Mercuro NJ, Yen CF, Shim DJ, Maher TR, McCoy CM, Zimetbaum PJ, et al. Risk of QT interval prolongation associated with use of hydroxychloroquine with or without concomitant azithromycin among hospitalized patients testing positive for coronavirus disease 2019 (COVID-19). JAMA Cardiol. 2020;1:e201834. https ://doi.org/10.1001/jamacardio.2020.1834. 